\title{
The Effect of Mobile-Assisted Language Learning Environment on EFL Students' Academic Achievement, Cognitive Load and Acceptance of Mobile Learning Tools
}

\author{
Omer Ozer ${ }^{1 *}$, Figen Kılıç ${ }^{2}$ \\ ${ }^{1}$ School of Foreign Languages, Adana Science and Technology University, Adana, TURKEY \\ ${ }^{2}$ Education Faculty, Mersin University, Mersin, TURKEY
}

Received 11 December 2017 - Revised 10 April 2018 - Accepted 20 April 2018

\begin{abstract}
This study reports on the investigation of the effect of mobile assisted learning environment on academic achievement, acceptance of mobile learning tools and cognitive load of EFL students. This study used a mixed methods approach which involves the collection and analysis of quantitative and qualitative data to identify the effect of mobile learning in a foreign language learning environment. Quantitative data were collected from 63 foreign language learners via an academic achievement test, cognitive load scale and mobile learning tools acceptance scale, before and after a sixweek intervention period. Following the intervention, eight students from the experimental group answered open-ended questions about their experience during group interviews. Results showed a significant difference in academic achievement and mobile learning tools acceptance level of students in favor of the experimental group. The study also showed that although the students learning a foreign language in mobile assisted learning environment were not cognitively overloaded, students in the control group were. The themes emerged from the qualitative data point to the positive and negative sides of the mobile-assisted learning environment.
\end{abstract}

Keywords: academic achievement, acceptance of mobile learning devices, cognitive load, foreign language teaching, mobile learning

\section{INTRODUCTION}

The ubiquity of mobile devices has greatly changed the way individuals communicate, work and study in the $21^{\text {st }}$ century. As smart phones and tablets become more easy-to-use and powerful, they will be an effective learning tool both inside and outside classrooms (Lin, Chen, \& Liu, 2017; Sung, Chang, \& Liu, 2016). Today, mobile devices are taking on a greater prominence in educational institutions (Hu \& McGrath, 2011; Jin \& Zhirui, 2017; Pegrum, Oakley, \& Faulkner, 2013; Soruç \& Tekin, 2017; Vazquez-Cano, 2014). The proliferation of mobile devices is constantly changing the way we interact and learn. Wang, Wiesemes, and Gibbons (2012) define mobile learning (m-learning) simply as learning anywhere, anytime through mobile devices.

The effective use of mobile devices necessarily requires understanding the scope of the contextual features of educational institutions with regard to implementation (Crompton Olszewski, \& Bielefeldt, 2016). In the next fifteen years, mobile learning tools will undoubtedly become more integrated with mainstream education. Most students around the world will be able to bring and utilize their own smart devices since the necessary technology is expected to be more accessible, affordable and connected than it is today (Conejar \& Kim, 2014; Crompton et al., 2016). The strength of mobile devices lies in the fact that they can be used for learning purposes. However, as is the case in much of the relevant literature, this paper also emphasizes that simply integrating mobile devices into learning process does not guarantee better learning. Integrating powerful mobile devices into instruction must also be accompanied by a pedagogical shift in order for students to benefit maximally from their use in the classroom.

(C) 2018 by the authors; licensee Modestum Ltd., UK. This article is an open access article distributed under the terms and conditions of the Creative Commons Attribution License (http://creativecommons.org/licenses/by/4.0/). $\square$ ozeromer.tr@gmail.com (*Correspondence) $\square$ figendamla@yahoo.com 


\section{Contribution of this paper to the literature}

- This study focuses primarily on how EFL university students' language skills are affected in a mobileassisted learning environment.

- $\quad$ Both teacher-paced and student-paced applications were used in this study. A discussion of their potential advantages, disadvantages and the practical concerns related to classroom implementation is provided. This can help teachers better design mobile-assisted learning environments.

- This study also helps schools develop policies to control the use of mobile devices.

Like computer-assisted language learning, m-learning has also featured in the evolution foreign language learning has undergone over the past several years. Research has demonstrated that mobile learning technologies can be effectively used in vocabulary teaching (Chen \& Li, 2010; Kim \& Kim, 2012), to facilitate grammar teaching and help improve reading skills (Hsu, Hwang \& Chang, 2013) and to enhance writing skills (Ivić \& Jakopec, 2016). Other studies have shown that mobile learning tools can offer learners the chance to listen and record their own voice (Hwang, Huang, Shadiev, Wu, \& Chen, 2014), which is associated with improvement of pronunciation and communication skills. Furthermore, mobile learning tools provide multimedia interaction opportunities and a collaborative environment whereby learners can develop and improve their speaking skills (Hwang et al., 2014; Hwang, Shih, Ma, Shadiev, \& Chen, 2016; Liu \& Chu, 2010). Multimedia content can be beneficial to students by enabling multimodal learning as long as the methods of delivery, storage and presentation are adjusted to the capabilities of mobile learning tools and the cognitive capacity of students (Milutinović, Labus, Stojilkovic, Bogdanovic, \& Despotovic-Zrakic, 2015). Hence mobile applications for language learning ought to be designed to support mobile learning methodologies and to cover learning content.

Integration of mobile devices to support language practice and facilitate language learning have also extensively investigated. Some studies have found that mobile phones and tablets, when used appropriately, may assist students in improving academic achievement (Huang, Lin \& Cheng, 2010; Ivić \& Jakopec, 2016; Lu \& Yang, 2018). In a meta-analysis, Sung, Chang, and Liu (2016) found that using mobile devices in education had a medium effect size for learning achievement. That is to say, most of the students using a mobile device performed significantly better on dependent variables related to achievement than the students not using mobile devices. Hwang et al. (2014) found that language students had positive perceptions and intentions toward learning activities using mobile learning tools; thus, students were motivated to practice foreign language skills more when using a mobile learning tool. An increase in motivation to learn using mobile devices is supported by a range of studies, including work by Ciampa (2013), Huang, Lin, and Cheng (2010), Rogers (2011), and Zheng, Chen, and Kong (2017). However, a mobile phone can be a potential distraction as Froese et al. (2012) indicated that students who freely texted during the lesson scored much lower than those who muted their phones during instruction.

Integrating mobile devices with multiple teaching/learning strategies is necessary for a better learning achievement (Sung, Chang \& Yang, 2015). As Deegan (2015) claimed, mobile applications are rarely developed by teachers or pedagogues. However, it should be noted that teachers have the liberty to choose apps which best serve their purposes in classrooms. Thanks, in part, to the growing number of possible mobile applications available for language learning, the number of language teachers who can design mobile-assisted language learning environments has increased.

\section{Theoretical Framework}

The main theoretical framework of the current study is based on cognitive load theory, and its role in instructional design, along with the technology acceptance model.

Cognitive load theory is concerned with the conditions under which learners can best absorb and retain new information without overwhelming their limited short term memory resources. Cognitive load is typically increased when learners are dealing with complex problems for which they need to use their schemas (Paas, van Gog, \& Sweller, 2010). If they haven't acquired the necessary schemas, or if the instructional procedures are poorly designed, such that the extraneous or intrinsic, rather than germane, types of cognitive load are involved, working memory will not be able to successfully retain all the bits of information contained in the task, thereby hindering effective learning (Paas \& Ayres, 2014; Paas, Tuovinen, Tabbers, \& Van Gerven, 2003). This theory may help explain how students, with similar language abilities, who are exposed to the same course content within different learning environments, handle information with varying degrees of difficulty. Especially during the last two decades, researchers have pointed out that the cognitive load of learners can be a good indicator of the efficacy of new teaching methods or learning technologies (Deegan, 2015; Paas, van Gog \& Sweller, 2010; van Merrienboer \& Sweller, 2005). As mobile learning may have unique characteristics that traditional acceptance theories have difficulty in addressing, a model specifically for technology acceptance was preferred in this study to explore EFL students' willingness to use mobile learning tools. 


\section{Statement of the Problem}

Mobile devices have become learning tools with great potential for use both inside and outside of the traditional school setting. Although there have been qualitative analyses of the use of mobile devices in school settings, systematic quantitative analyses of the effects of mobile-assisted learning environments are lacking (Sung, Chang, \& Liu, 2016; Vazquez-Cano, 2014). Milutinović et al. (2015) asserted that most of the studies in the m-learning field spotlighted a single aspect or a single activity of mobile-assisted language learning. In spite of the fact that mobile devices are increasingly used in school settings, there is a dearth of research on the overall effectiveness of mobileassisted language learning (Sung, Chang, \& Yang, 2015).

Within the framework of mobile devices as learning tools, m-learning may affect the extent to which learners can benefit from the environment and how they handle information overload within different learning environments. The purpose of this research is fourfold. The first goal is to determine the effect of the intervention on the students' academic achievement. Secondly, this study tries to determine the extent to which mobile learning tools are accepted by students. Thirdly, this paper examines the impact of mobile assisted language learning on students' cognitive load. Lastly, the paper tried to address what the students in the experimental group think about the process of mobile assisted language learning. Considering the related studies on EFL students' learning, both degree of acceptance of mobile learning tools and cognitive load might be strong predictors of academic achievement, Based on the literature review, the following research questions were asked in this study:

(1) What is the effect of mobile-assisted language learning environment on the students' academic achievement?

(2) How different is the mobile learning tools acceptance scores of students in the experimental and control groups?

(3) How different is the cognitive load of the students in the experimental and control groups?

(4) How do the students in the experimental group perceive the mobile-assisted learning environment?

\section{METHODOLOGY}

This study followed an intervention mixed methods approach (Creswell, 2015), in which both quantitative and qualitative data were collected to enable an in-depth study of the efficacy of the mobile-assisted language learning environment, which only students in the experimental group experienced. The present study used both quantitative and qualitative data to better describe and interpret the ways in which the teaching and learning processes take place in the mobile-assisted learning environment. Quantitative data were collected via questionnaires in order to address to explore the difference in students' academic achievement, mobile learning tools acceptance scale and cognitive load. Qualitative data were collected by means of a semi-structured focus group interview which allowed for an in-depth examination of participants' perspectives on the effectiveness of the learning environment and the identification of the sources of cognitive load.

\section{Participants}

Purposeful sampling was selected as the sampling method for this study. In the process of sampling selection, the criterion sampling was also applied to select the subjects. Participants in this study were 63 university students enrolled in two different classes in a year-long compulsory English language preparatory programme. This study was carried out throughout one semester with two compulsory foundation year classes within the preparatory English language study programme. All students were at the A2 level of English, according to the CEFR guidelines. Table 1 shows the participants' profile. 
Table 1. Participants' Profile

\begin{tabular}{ccccc}
\hline & Experimental $(n=32)$ & \multicolumn{2}{c}{$\begin{array}{c}\text { Control } \\
(n=31)\end{array}$} \\
\hline Variables & $\boldsymbol{F}$ & $\%$ & \multicolumn{2}{c}{$\%$} \\
\hline Gender & & & & \\
Male & 19 & 59.4 & 19 & 61.3 \\
Female & 13 & 40.6 & 12 & 38.7 \\
\hline Age & & & & 32.3 \\
18 & 8 & 25 & 10 & 38.7 \\
19 & 11 & 34.4 & 12 & 19.4 \\
20 & 9 & 28.1 & 6 & 9.7 \\
21 & 2 & 6.3 & 3 & 0 \\
\hline $22+$ & 2 & 6.3 & 0 & \\
\hline Field of Study & & & & \\
Engineering & 20 & 62.5 & 21 & 67.7 \\
Business & 10 & 31.3 & 8 & 25.8 \\
Tourism & 2 & 6.3 & 2 & 6.5 \\
\hline
\end{tabular}

The experimental group consisted of 32 students (13 females) and the control group was composed of 31 students (12 females). Most students in both groups were 19 years old. Before the intervention, experimental and control groups' students' MLTAS and academic performance test scores were tested to ensure that the normality assumption is fulfilled for the two groups.

As for the participants of the group interviews, eight students were chosen from the experimental group using the extreme case sampling methods. Of all the interviewees, four were underachievers and the rest were high achievers in the academic performance test.

\section{Data Collection and Analysis}

In parallel to the research questions, the data of this study were obtained through four channels by both experimental and control groups. These instruments and the research questions they refer to are specified below.

\section{Academic performance test}

A test examining students' academic knowledge and performance was developed. This test is composed of two sections. The first section contains multiple choice questions to assess listening, reading and language use. Section two assesses oral production and writing skills based on detailed grading rubrics for each skill. To do so, a pilot test containing 158 items was generated and administered to 97 students. The results were analyzed to ensure validity and reliability of the instrument. Following necessary modifications, another pilot test was administered to 126 students. The results were analyzed again for item discrimination and item difficulty index. The reliability of the academic performance test was measured using the Kuder-Richardson Formula 20 (KR20). The KR20 reliability coefficient for academic performance test was found to be 0.947 .

The first section of the academic performance test comprised three subtests - listening reading and language use. This section had a total of 60 items; 20 items for listening, 20 items for reading, and 20 items for use of language (vocabulary and grammar).

The second section comprised a writing and speaking task, which were evaluated using two rubrics: one based on writing performance and the other based on oral production. The assessment of writing and speaking, by its nature, is not limited to one correct answer. Considering the main criteria of analytic rubrics, two initial rubrics were designed to categorize students' performance in writing and speaking. Upon revision of the first versions of the rubrics, based on a pilot study and the opinion of experts, the rubrics took their final forms. The rubric for oral production skills consisted of five categories: pronunciation, vocabulary, sentence structure, fluency and comprehension. The writing rubric also comprised five categories, namely, clarity, vocabulary, language control, punctuation and organization.

In this study, students' academic performance score was found by adding the score from the first and second sections. Each of the 5 elements assessed - language use, listening, speaking, reading and writing - accounted for one-fifth of participants' academic performance score. 


\section{Mobile learning tools acceptance scale}

The Mobile Learning Tools Acceptance Scale (the MLTAS), developed by Ozer and Kılıç (2017) was used to assess the extent to which students accept mobile learning tools. The MLTAS consists of 19 items scored on a fivepoint Likert scale. The development of this instrument began with a review of studies using technology acceptance scales.

This review revealed that 33 items are commonly used to measure technology acceptance. These 33 items were modified for the current study to make them suitable for mobile learning tools. From an original pool of 33 items, the scale was reduced to 25 items after the exploratory factor analysis and was reduced from 25 to 19 items after the confirmatory factor analysis. This scale shows good reliability with a Cronbach's Alpha of 0.83 . The MLTAS serves as a means of predicting learners' level of acceptance of mobile learning tools. Of the 19 items, five each measured "contribution to foreign language learning," "negative perception" and "voluntariness of use", while four items covered "perceived ease of use."

\section{Cognitive load scale}

The relationship between learners' performance in a mobile-assisted language learning environment and cognitive load scores were assessed by means of an adaptation of a cognitive load scale. A nine-point symmetrical category scale, developed by Paas and Merrienboer (1993), was used in this study. In this measure, participants provide a self-report of their mental effort by marking a numerical value, ranging from 1 (very, very low) to 9 (very, very high). Kılıç and Karadeniz (2004) have adapted the Subjective Rating Scale by Paas and Merrienboer (1993) to Turkish. For the reliability of the adapted version, the Cronbach's Alpha coefficient was found to be 0.78. Throughout the six-week study period, participants were required to indicate their level of mental effort immediately after every mobile-assisted learning activity. Each student's cognitive load score was calculated by averaging all the cognitive load scores obtained after each learning activity.

\section{Focus group interviews}

In semi-structured focus group interviews, 8 students from the experimental group were asked to answer several questions related to their experience in the mobile-assisted language learning environment. All the interviewees were asked for their permission to audio-record the interview. In order to determine expert validity, the items in the interview were sent to two experts to be examined for clarity. In the light of the feedback provided, the interview questions were revised and finalized. The questions were mostly centered on identifying strengths and weaknesses while learning in a mobile-assisted environment Due to ethical considerations, the interviewees' identities were anonymized. In order to select interviewees, the study used extreme-case sampling based on results from the academic performance test. The interviews were held in two sessions with four students in each. Analysis of this data involved four steps. In the first step, the two digitally recorded interviews were transcribed verbatim. In the second step, an initial coding of interview transcripts was done. In the third step, the emergent themes were identified. Finally, the themes were reviewed and revised to prevent overlap. Miles and Huberman's (1994) statistical technique for measuring inter-rater reliability was used. Based on 86 agreements and 17 disagreements between the coders while identifying the themes, a reliability of 0.83 was calculated. Disagreements in regard to identifying categories were discussed and resolved before both the researchers proceeded with coding the rest of the qualitative data.

\section{Procedure}

This study was carried out throughout one semester with two compulsory foundation year classes within the preparatory English language study programme. A one-week pilot study was completed in the fall semester of 2015 at a state university to observe and forestall any possible interference. After several improvements based on the evaluation of the pilot study, the start of the intervention was scheduled for the second week of the spring semester of 2016. Before the intervention, students in both the experimental and control groups completed the academic performance test and the MLTAS.

After the pre-tests were collected, the 32-hour intervention began. During the six-week intervention, the cognitive load scale was administered immediately after each activity. The experimental group learned in a mobileassisted language learning environment whereas the control group learned without any mobile learning technology. Figure 1 presents the experimental process. 


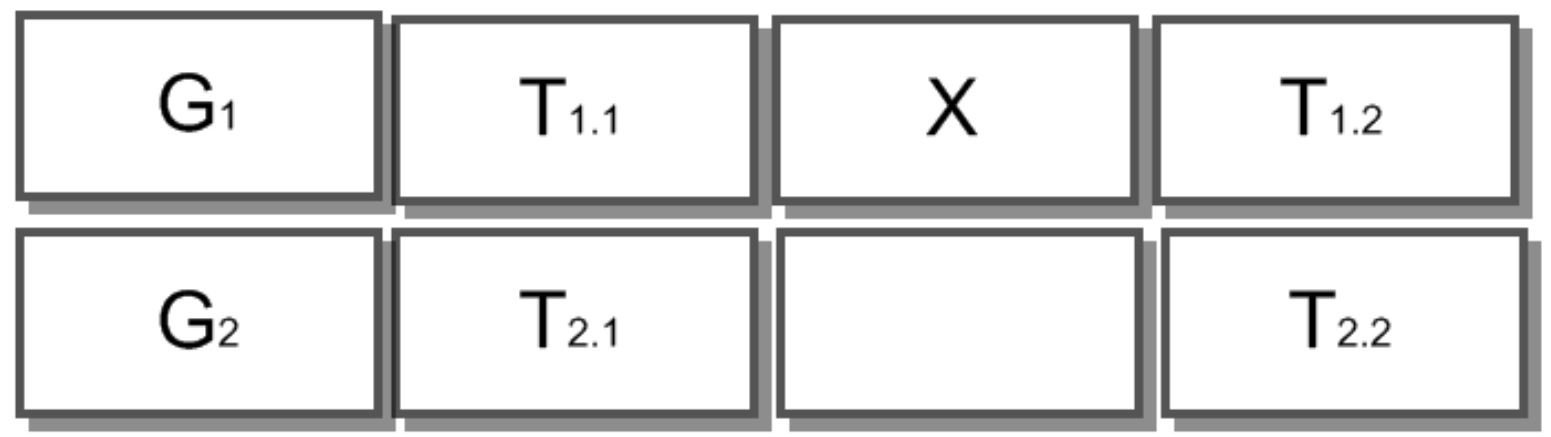

Figure 1. Experimental Process of the Study

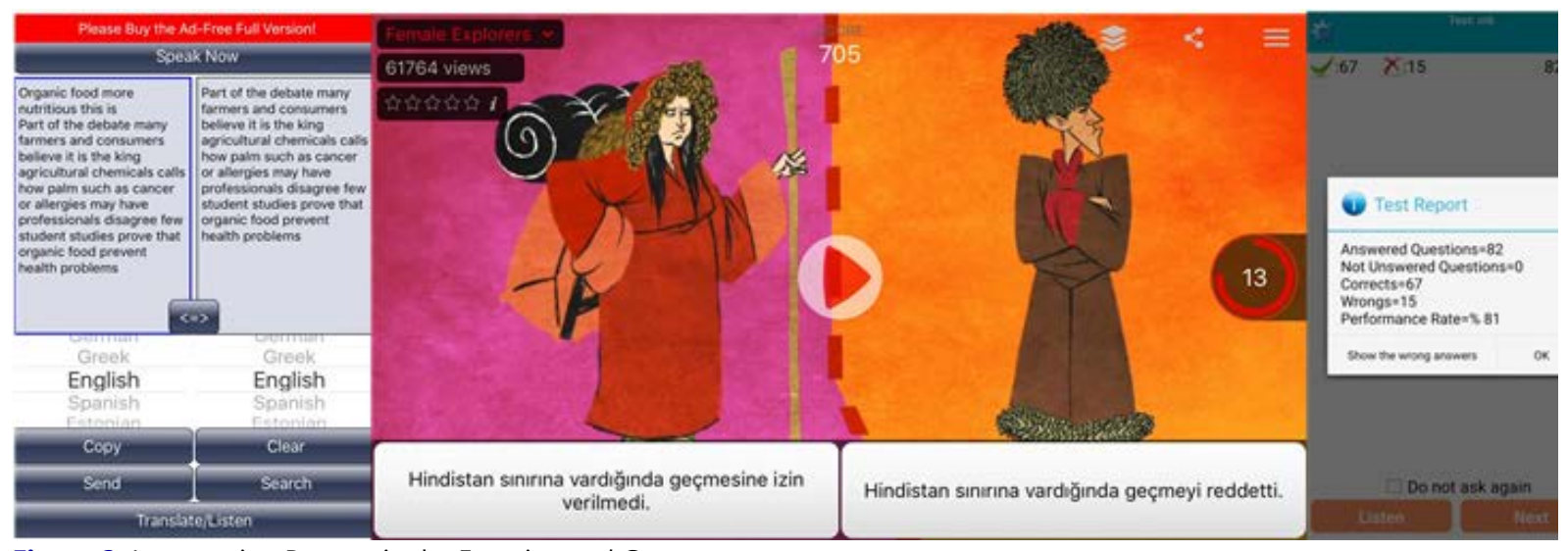

Figure 2. Intervention Process in the Experimental Group

$\mathrm{G}_{1}$ stands for the experimental group whose learning environment included course books, smart board, online and offline learning materials along with extensive use of mobile phones. $G_{2}$ refers to the control group whose classes were conducted under the same conditions as $G_{1}$, except that the online/offline learning materials and mobile phones were not present in the learning environment. $T_{1.1}$ and $T_{2.1}$ represent the pre-tests and $T_{1.2}$ and $T_{2.2}$ indicate the post-tests completed by the experimental and control groups, respectively. $\mathrm{X}$ represents the experimental intervention where students learned the content in a mobile-assisted foreign language learning environment.

The intervention was a mobile-assisted learning environment in order to facilitate students' listening, speaking, reading and writing skills along with vocabulary and language structures. The experimental group had an intervention that used course books, smart boards and mobile devices. The learning activities that were designed in the study were supported by a variety of mobile applications. The mobile applications included Johnny Grammar's Word Challange, Practice English Grammar and GrammarUp (to practice language structures), KelimeEzber, Tureng, and Wordweb (for vocabulary), Cambridge Advanced Dictionary and Longman Dictionary of Contemporary English (Online Dictionaries), BBC - 6 Minute English and Learn English with BBC (podcasts), Speaking Pal, Speech-to-text-translator TTS, Tureng and Longman Dictionary of Contemporary English (pronunciation), todaysmeet.com (backchannel for online conversation), SocrativeStudent, Quizizz and Kahoot! (classroom response systems for formative assessment), Youtube (video-sharing website), VoScreen (a tool for developing understanding of different languages), GoogleTranslate (multilingual machine translation service).

During the six-week intervention, 31 students representing the control group were in a learning environment which included the same materials and equipment that were used for the experimental group except for the mobile devices. As the application of mobile learning tools was the key variable of the study, the control group students used printed dictionaries, course books and smart boards.

After the intervention, the academic performance test and the MLTAS were administered. After that, semistructured interviews were conducted with the experimental group students so as to more deeply understand the processes students went through in the learning environment. The intervention process is shown in Figure 3. 


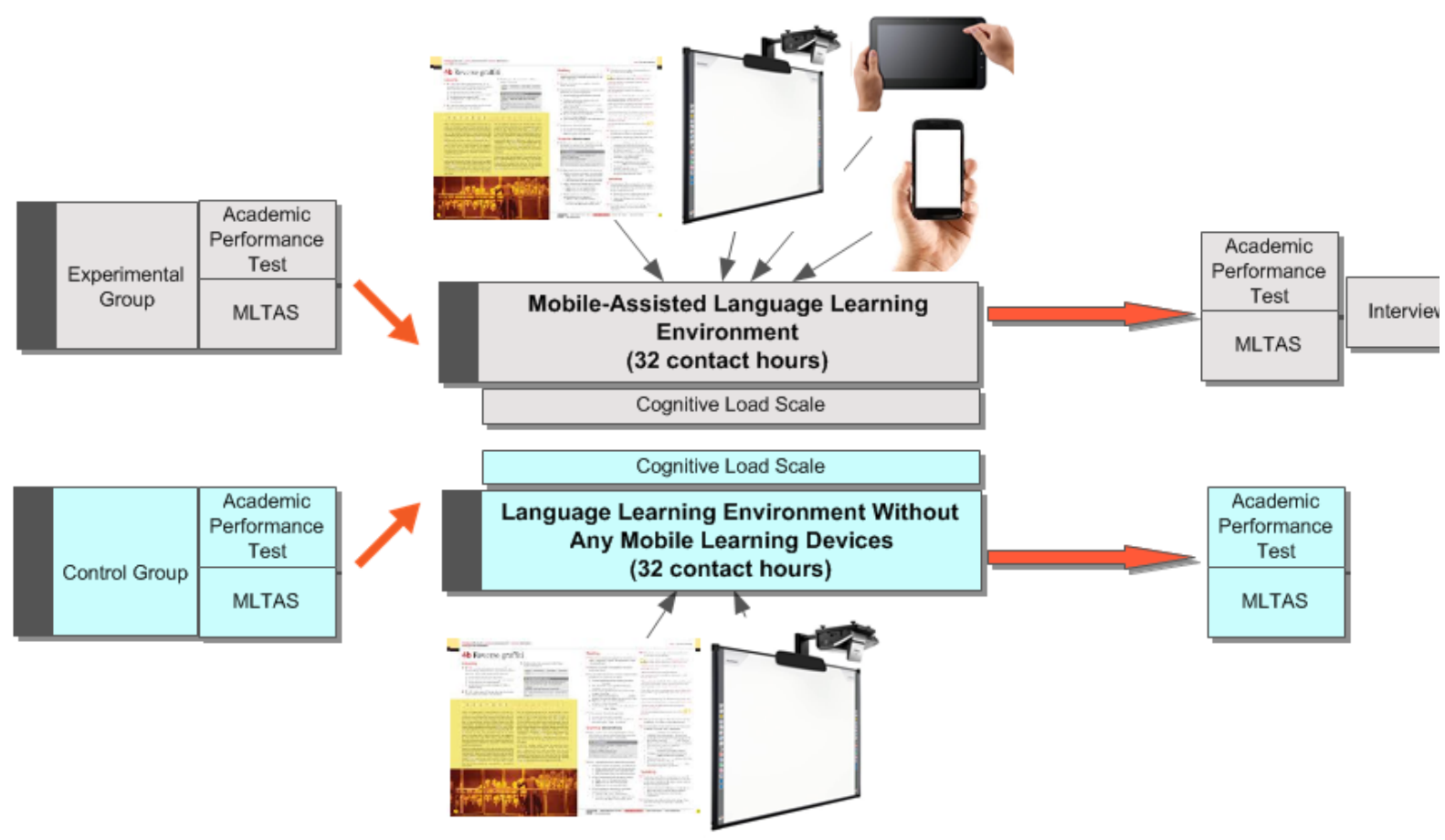

Figure 3. Intervention Process

Table 2. The t-test results for the academic achievement gain scores

\begin{tabular}{lccccccc}
\hline Group & $\mathbf{N}$ & Pre-test $\overline{\boldsymbol{X}}$ & Post-test $\overline{\boldsymbol{X}}$ & Gain Score $\overline{\boldsymbol{X}}$ & SD & $\mathbf{t}$ & $\mathbf{P}$ \\
\hline Experimental & 32 & 50.23 & 67.09 & 16.86 & 6.04 & $5.75^{*}$ & .000 \\
\hline Control & 31 & 49.59 & 58.36 & 8.77 & 5.06 & & \\
\hline${ }^{*}<<.01$ & & & & & &
\end{tabular}

Table 3. The t-test results for the MLTAS gain scores

\begin{tabular}{lccccccc}
\hline Group & N & Pre-test $\overline{\boldsymbol{X}}$ & Post-text $\overline{\boldsymbol{X}}$ & Gain Score $\overline{\boldsymbol{X}}$ & SD & t & P \\
\hline Experimental & 32 & 73.97 & 78.34 & 4.38 & 9.47 & $2.81^{*}$ & .007 \\
\hline Control & 31 & 74.74 & 72.52 & -2.23 & 9.15 & & \\
\hline${ }^{*} \mathrm{p}<.01$ & & & & & &
\end{tabular}

\section{RESULTS}

\section{Analysis of Quantitative Data}

In order to answer the first research question which investigates the effect of mobile-assisted language learning environment on the students' academic achievement, academic performance test gain scores were analyzed and the results are presented in Table 2.

As indicated from Table 2, it was found that the students in a mobile-assisted environment outperformed the control group students in regard to academic achievement gain scores. Results of an analysis of variance and t-test also showed that gender and field of study had no significant effect on the students' academic achievement gain scores. Also a large effect size was calculated for the magnitude in difference in means (Cohen's d $=1,065$ ).

The second research question aimed to investigate whether there is a significant difference in the level of MLTAS between experimental and control group students. The results of the t-test for both groups are shown in Table 3.

The results of the analysis demonstrated that those in the experimental and control groups showed different levels of acceptance of mobile learning tools following the intervention. At post-test, those in the experimental group showed an increase in MLTAS scores, which differed significantly from the post-test MLTAS scores of those in the control group. Results of an analysis of variance and t-test showed that gender and field of study had no significant effect on the students' MLTAS gain scores. 
Table 4. Results of cognitive load scale assessment and t-test

\begin{tabular}{llllll}
\hline Group & $\mathbf{N}$ & $\overline{\boldsymbol{X}}$ & $\mathbf{S D}$ & $\mathbf{t}$ & $\mathbf{p}$ \\
\hline Experimental & 32 & 4.08 & 1.16 & $-4.191^{*}$ & .000 \\
\hline Control & 31 & 5.60 & 1.68 & & \\
\hline${ }^{*} \mathrm{p}<.01$ & & & & \\
\hline
\end{tabular}

${ }^{*} \mathrm{p}<.01$

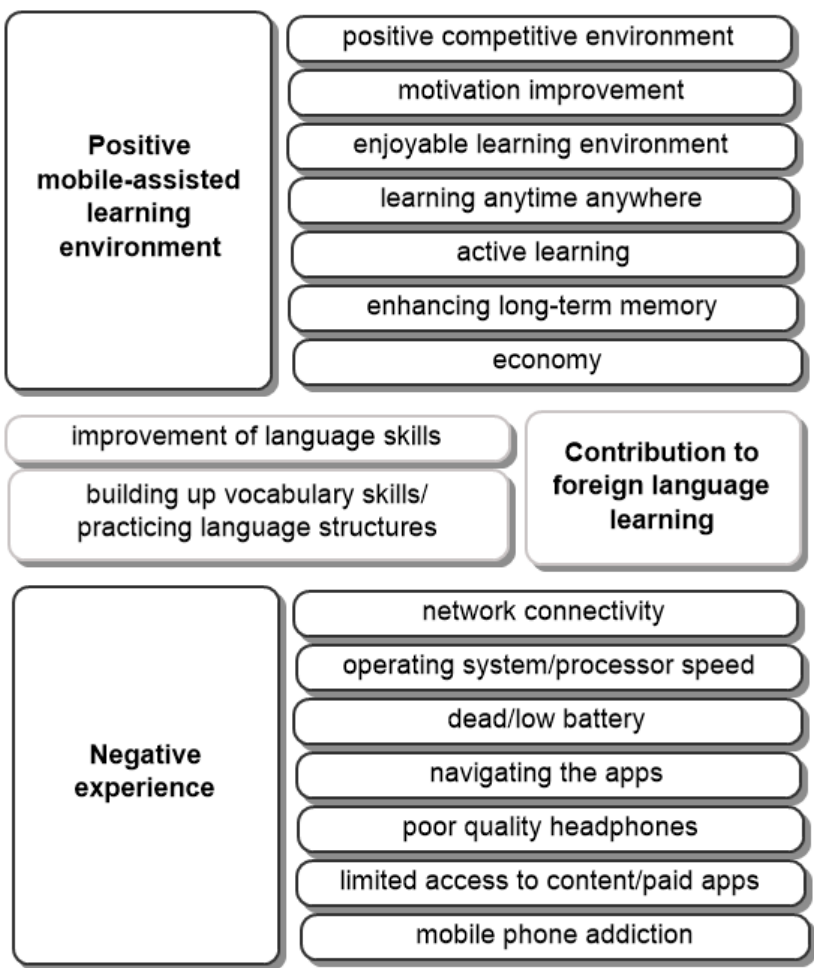

Figure 4. Themes and sub-categories with respect to students' m-learning experience

In an attempt to answer the second research question, the perceived mental effort of the two groups of students were measured after each activity during the intervention process and the collected data were analyzed using an independent samples t-test. Table 4 provides means and standard deviations from the analysis with respect to the cognitive load scale.

As seen in Table 4, students in the experimental group had lower cognitive load compared to those in the control group. Results of an independent samples t-test confirmed that this difference was statistically significant. With regard to the mean amount of mental effort invested, only three students in the experimental group selfreported high mean mental effort to solve the problems while 19 students in the control group did so. Results of a one-way ANOVA and t-test showed that gender and field of study had no significant effect on the students' cognitive load.

\section{Analysis of Qualitative Data}

Figure 4 presents the themes and sub-themes that emerged from interviewees' responses to questions related to their mobile-assisted foreign language learning experience.

As seen in Figure 4, the themes that emerged were "positive mobile-assisted learning environment," "contribution to foreign language learning" and "negative experience." These themes are interrelated and no particular theme is of higher value. Participants identified a number of their experiences and coping strategies. A quote for each theme is included below to support the interpretation. The first theme focused on the positive aspects of a mobile-assisted language learning environment. Many students, like the following participant, reported experiencing distinct advantages when learning via mobile phones:

I think it is enjoyable because there was, as I said, a competitive [learning] environment. And the [the list of] top five rankings pops up, people compete [then]. I don't get bored. (EG-5F).

The second theme deals with the contribution to foreign language skills. More specifically, this theme explored how mobile-learning activities affected the foreign language learning process. One participant said: 
Our writing [skills have] improved. As our vocabulary and grammar expanded, our writing [skills] has also improved naturally. We started to use more words, different words, not the same ones repeatedly. We started to use different grammars [a variety of language structures]. Not only [did we use] the active sentences but also the sentences in passive and with relative clauses. We did not improve only in writing [rather] we started to use them in speaking too. (EG-3-F).

The negative experiences students had in the mobile assisted learning environment comprised the third theme. It encapsulates seven sub-themes from network connectivity to mobile phone addiction. One of the participants expressed his experience in the following quote:

Apps which we can use outside the school help us more when they run offline. Because umm we cannot always access internet, so we have times when we don't have any [network] connection. We cannot use online apps then. That's why an offline app is more useful for us. [I mean] in those situations. [However,] in the classroom online apps are more helpful. (EG-7M)

\section{DISCUSSION AND CONCLUSIONS}

This study looked into how students are affected when learning in a mobile-assisted environment in terms of academic achievement, acceptance of mobile learning tools and cognitive load. Additionally, group interviews were conducted in order to probe and uncover the underlying beliefs of students towards mobile-assisted foreign language learning.

Unlike most previous research on mobile learning, the present research took a holistic perspective on language learning in order to identify the effects of mobile learning tools on academic achievement - that is, the emphasis was on all four language skills. The results of quantitative data analysis for academic achievement showed that only students in the experimental group experienced a statistically significant gain in academic achievement, a finding which was further supported by a large effect. Importantly, these results were not affected by the participants' field of study. It was also concluded that learning performance in a mobile-assisted environment did not vary by gender. This result is consistent with the results of Chung and Chang (2017). It is clear from these findings that the mobile-assisted learning environment has a significant positive effect on students' academic achievement. This conclusion is supported by a number of past research, including work by Bahrani (2011), Chen and Li (2010), Hsu, Hwang, and Chang (2013), Hwang, Huang, Shadiev, Ivić and Jakopec (2016), Hwang et al. (2014), Kim and Kim (2012), Lu and Yang (2018), Stockwell (2010), Sung, Chang, and Liu (2016), and Sung, Chang, and Yang (2015).

A significant increase was observed in acceptance rate of the students in the experimental group, indicating that these students accepted mobile learning technologies significantly more than those in the control group following the intervention period. Students in the control group actually showed a slight decrease in their acceptance of mobile learning technologies. This may be due to the fact that students did not use their mobile devices in class for a period of six weeks. The increase in the MLTAS gain scores of students in the experimental group, however, may be due to the pleasure and usefulness they perceived in the mobile-assisted learning environment. A possible positive relation might be assumed between the increase in academic achievement and the acceptance rate of mobile learning tools. Liaw, Hatala, and Huang (2010) indicated that factors such as encouragement of learners' autonomy and system functions that enrich interaction are predictive of acceptance of mobile learning technologies. When students enjoy using the mobile learning tools for retrieving online content and for gathering online resources they tend to keep using them. The more motivated the students are towards learning through mobile phones, the more likely for them to gain better academic achievements.

To broadly understand the students' cognitive load, students' scores on the cognitive load scale were examined. It was found that students in the experimental group generally perceived a low level of mental effort when completing learning activities, whereas cognitive overload was reported by students in the control group. Integrating self-paced and teacher-based mobile activities turned language learning into a more engaging and interactive process. When students engaged in activities, the teacher monitored students' learning and encouraged autonomous learning. This result corresponds with results of past studies which reported a decline in cognitive load of students in a mobile-assisted learning environment (Homer, Plass, \& Blake, 2008; Klatzky, Wu, Shelton, \& Stetten, 2008; Shadiev, Hwang, Huang, \& Liu, 2015). This finding also contradicts results of prior studies which did not find a significant decrease in students' cognitive load (Chu, 2014; Wong, Leahy, Marcus, \& Sweller, 2012). One of the reasons why students who learned in the mobile-assisted language learning environment obtained favorable learning achievements with no cognitive overload may be activation of prior knowledge via mobile learning tools. Huang (2018), Kalyuga, Ayres, Chandler, and Sweller (2003), and Wong et al. (2012) indicated that students with low levels of prior knowledge may experience cognitive overload because of the large amount of simultaneous mental processing that is required under these conditions. Collaborative activities done in this study focused 
heavily on newly created knowledge, thereby allowing students to reflect on areas where they had difficulties. Teacher-based collaborative activities may be especially effective at reducing the mental efforts students devoted since students shared experience and knowledge in order to complete these tasks. As in action learning sets, these kinds of activities can involve inquiry-oriented practice towards obtaining meaningful data, and may help reduce cognitive load, thereby allowing students to make effective learning decisions. Additionally, Salvetti and Bertagni (2016) concluded that activation of prior knowledge and learning by doing based on knowledge visualization via mobile learning tools can leave students with a profound and memorable experience. This knowledge visualization can help students reduce the mental effort involved in complex tasks, especially.

The interview data yielded key information regarding the beliefs about the mobile language learning environment. The themes which emerged from this data included "positive mobile-assisted learning environment," "contribution to foreign language learning" and "negative experience." In a positive mobile-assisted learning environment, students can learn at their own pace and enjoy learning. Numerous studies support the finding that with regular and effective use of mobile learning tools, students are more likely to enjoy learning (Bahrani, 2011; Başoğlu \& Akdemir, 2010; Fernandez-Lopez, Rodriguez-Fortiz, Rodriguez-Almendros, \& Martinez-Segura, 2013; Gingerich \& Lineweaver, 2014; Motiwalla, 2007; Rogers, 2011) and better perform in the subject (Fleischer, 2012; Hwang \& Chang, 2015; Sung, Chang, \& Liu, 2016; Sung, Chang, \& Yang, 2015). Contribution to foreign language learning was another theme that emerged from the interview data. Based on the results of the interviews, reading, writing and listening were the most affected skills, respectively by the mobile learning environments. In similar studies, researchers found that mobile learning can help students improve their vocabulary and language structures (Bahrani, 2011; Chen \& Chung, 2008; Huang, Yang, Chiang, \& Su, 2016; Stockwell, 2010; Sung, Chang, \& Yang, 2015), as well as their proficiency in the four major language skills (Bahrani, 2011; Chang \& Hsu, 2011; Demouy \& Kukulska-Hulme, 2010; Kim, 2013; Wang \& Smith, 2013). As for negative experiences, the main issues reported by students were problems with battery life, internet connection, operating system/processor speed, earphones/microphones, mobile application navigation and smartphone addiction. This result corresponds with studies showing that mobile learning activities can be affected negatively by technical problems involving battery life (Milutinovic et al., 2015; Rogers, 2011), internet connection problems (Farley et al., 2015; Godwin-Jones, 2011; Hanafi \& Samsudin, 2012), operating system/processor speed (Farley et al., 2015; Rogers, 2011), earphone/microphone-based problems (Ally, 2013), mobile app navigation (Conejar \& Kim, 2014; Milutinovic et al., 2015; Rogers, 2011) and smartphone addiction (Griffiths, 2013; Hadlington, 2015; Hawi \& Samaha, 2016; Ophir, Nass \& Wagner, 2009; Samaha \& Hawi, 2016). Recent studies exploring the effects of classroom mobile phone use on students' academic achievement report that mobile phones can be distracting and information processing can be impeded if students text or post to social media in the classroom (Calderwood, Ackerman \& Conklin, 2014; Kuznekoff \& Titsworth, 2013; Rogers, 2011; Unesco, 2012). For this reason, teachers are expected to check the students' devices carefully before the activities and fix or replace a device when necessary in accordance with the requirements of the activity. To sum up, mobile learning technologies have clear benefits for language learning. A profound understanding of the nature of motivation and acceptance of technology in a mobile-assisted language learning environment can be used to enhance academic achievement. It is reasoned that the mobile-assisted learning environment has a positive effect on students' acceptance, cognitive load and academic performance. When students enjoy using mobile learning tools, they tend to keep using them; and, the more students use these tools, the more likely they are to experience academic gains. As long as the language learning environment offers equal access to every student regardless of ability and flexible learning opportunities, students are expected to perform better academically. Consequently, germane cognitive load increases since students are more motivated to participate in activities and as it is easier for the teacher to provide feedback via mobile learning tools. The findings of this study are helpful to those teachers who intend to design a mobile-assisted language learning environment and to those researchers who have been working on the effects of mobile learning tools on foreign language learning. In the meantime, since this study focuses primarily on how EFL university students' language skills are affected in a mobile-assisted learning environment, it is worth investigating the effects of similar learning environments on other subjects with younger age groups.

\section{LIMITATIONS}

Some limitations of the current work are worth mentioning. First, the study depended on the validity of the data collected from 63 EFL students during the spring semester in 2015-2016 academic year. The relatively small sample size may have underpowered some of the analysis. Another limitation was the fact that, only Android and IOS based freeware applications were used in this study. Future research will be needed to replicate these results using other operating systems and applications. Finally, this study is limited by the speed of internet connection provided by the institution. Unstable or slow network connection might have delayed task completion and motivation. 


\section{ACKNOWLEDGEMENTS}

This article is based on the first author's doctoral dissertation, supervised by the second author, submitted to Mersin University.

\section{REFERENCES}

Ally, M. (2013). Mobile learning: from research to practice to impact education. Learning and Teaching in Higher Education: Gulf Perspectives, 10(2), 1-10.

Bahrani, T. (2011). Mobile phones: just a phone or a language learning device? Cross-Cultural Communication, 7(2), 244-248. https:// doi.org/10.3968/j.ccc.1923670020110702.028

Başoğlu, E., \& Akdemir, O. (2010). A comparison of undergraduate students' English vocabulary learning: Using mobile phones and flash cards. Turkish Online Journal of Educational Technology, 9(3), 1-7.

Calderwood, C., Ackerman, P. L., \& Conklin, E. M. (2014). What else do college students “do" while studying? An investigation of multitasking. Computers $\mathcal{E}$ Education, $75, \quad 19-29$. https:// doi.org/10.1016/j.compedu.2014.02.004

Chang, C.-K., \& Hsu, C.-K. (2011). A mobile-assisted synchronously collaborative translation-annotation system for English as a foreign language (EFL) reading comprehension. Computer Assisted Language Learning, 24(2), 155180. https:// doi.org/10.1080/09588221.2010.536952

Chen, C. M., \& Chung, C.J. (2008). Personalized mobile English vocabulary learning system based on item response theory and learning memory cycle. Computers $\mathcal{E}$ Education, 51(2), 624-645, https:// doi.org/10.1016/j.compedu.2007.06.011

Chen, C.-M., \& Li, Y.-L. (2010). Personalised context-aware ubiquitous learning system for supporting effective English vocabulary learning. Interactive Learning Environments, 18(4), 341-364, https:/ / doi.org/10.1080/10494820802602329

Chu, H.-C. (2014). Potential negative effects of mobile learning on students' learning achievement and cognitive load - a format assessment perspective. Educational Technology E Society, 17(1), 332-344.

Chung, L.-Y., \& Chang, R.-C. (2017). The effect of gender on motivation and student achievement in digital gamebased learning: A case study of a contented-based classroom. EURASIA Journal of Mathematics Science and Technology Education, 13(6), 2309-2327. https:/ / doi.org/10.12973/ eurasia.2017.01227a

Ciampa, K. (2013). Learning in a mobile age: an investigation of student motivation. Journal of Computer Assisted Learning, 30(1), 82-96, http:/ / doi.org/10.1111/jcal.12036

Conejar, R. J., \& Kim, H-K. (2014). The effect of the future mobile learning: current state and future opportunities. International Journal of Software Engineering and Its Applications, 8(8), 193-200. https://doi.org/10.14257/ijseia.2014.8.8,18

Cresswell, J. W. (2015). A concise introduction to mixed methods research. USA: SAGE Publications, Inc.

Crompton, H., Olszewski, B., \& Bielefeldt, T. (2016). The mobile learning training needs of educators in technologyenabled environments. Professional Development in Education, 42(3), 482-501, https:/ / doi.org/10.1080/19415257.2014.1001033

Deegan, R. (2015). Complex mobile learning that adapts to learners' cognitive load. International Journal of Mobile and Blended Learning, 7(1), 13-24. https:// doi.org/10.4018/ijmbl.2015010102

Demouy, V., \& Kukulska-Hulme, A. (2010). On the spot: Using mobile devices for listening and speaking practice on a French language programme. The Journal of Open, Distance and e-Learning, 25(3), $217-232$. http:/ / doi.org/10.1080/02680513.2010.511955

Farley, H., Murphy, A., Johnson, C., Carter, B., Lane, M., Midgley, W., Hafeez-Baig, A., Dekeyser, S., \& Koronios, A. (2015). How do students use their mobile devices to support learning? A case study from an Australian regional university. Journal of Interactive Media in Education, 1. http:/ / doi.org/10.5334/jime.ar

Fernandez-Lopez, A., Rodriguez-Fortiz, M. J., Rodriguez-Almendros, M. L., \& Martinez-Segura, M. J. (2013). Mobile learning technology based on iOS devices to support students with special education needs. Computers $\mathcal{E}$ Education, 61, 77-90, https:/ / doi.org/10.1016/j.compedu.2012.09.014

Fleischer, H. (2012). What is our current understanding of one-to-one computer projects: a systematic narrative research review. Educational Research Review, 7, 107-122. https:/ / doi.org/10.1016/j.edurev.2011.11.004

Froese, A. D., Carpenter, C. N., Inman, D. A., Schooley, J. R., Barnes, R. B., Brecht, P. W., \& Chacon, J. D. (2012). Effects of classroom cell phone use on expected and actual learning. College Student Journal, 46(2), 323-332. 
Gingerich, A. C., \& Lineweaver, T. T. (2014). OMG! texting in class = u fail :( empirical evidence that text messaging during class disrupts comprehension. Teaching of Psychology, 41(1). https:/ / doi.org/10.1177/0098628313514177

Godwin-Jones, R. (2011). Emerging technologies mobile apps for language learning. Language Learning $\mathcal{E}$ Technology, 15(2), 2-11.

Griffiths, M. (2013). Adolescent mobile phone addiction: a cause for concern. Education and Health, 31(3), 76-78.

Hadlington, L. J. (2015). Cognitive failures in daily life: Exploring the link with Internet addiction and problematic mobile phone use. Computers in Human Behaviour, 51, 75-81. https:/ / doi.org/10.1016/j.chb.2015.04.036

Hanafi, H. F., \& Samsudin, K. (2012). Mobile learning environment system (MLES): The case of Android-based learning application on undergraduates' learning. International Journal of Advanced Computer Science and Applications, 3(3), 63-66.

Hawi, N. S., \& Samaha, M. (2016). To excel or not to excel: Strong evidence on the adverse effect of smartphone addiction on academic performance. Computers $\mathcal{E}$ Education, 98, 81-89. https:/ / doi.org/10.1016/j.compedu.2016.03.007

Homer, B. D., Plass, J. L., \& Blake, L. (2008). The effects of video on cognitive load and social presence in multimedialearning. Computers in Human Behavior, 24(3), 786-797. https:/ / doi.org/10.1016/j.chb.2007.02.009

Hsu, C-K., Hwang, G-J., \& Chang, C-K. (2013). A personalized recommendation-based mobile learning approach to improving the reading performance of EFL students. Computers $\mathcal{E}$ Education, 63, 327-336. https:/ / doi.org/10.1016/j.compedu.2012.12.004

$\mathrm{Hu}, \mathrm{Z} .$, \& McGrath, I. (2011). Innovation in higher education in China: are teachers ready to integrate ICT in English language teaching? Technology, Pedagogy and Education, 20(1), 41-49. https:// doi.org/10.1080/1475939X.2011.554014

Huang, C. S. J., Yang, S. J. H., Chiang, T. H. C. \& Su, A. Y. S. (2016). Effects of situated mobile learning approach on learning motivation and performance of EFL students. Educational Technology \& Society, 19(1), 263-276.

Huang, Y. M., Lin, Y. T., \& Cheng, S. C. (2010). Effectiveness of a mobile plant learning system in a science curriculum in Taiwanese elementary education. Computers $\mathcal{E}$ Education, 54(1), 47-58. https:/ / doi.org/10.1016/j.compedu.2009.07.006

Huang, Y-H. (2018). Influence of instructional design to manage intrinsic cognitive load on learning effectiveness. EURASIA Journal of Mathematics, Science and Technology Education, 14(6), 2653-2668. https://doi.org/10.29333/ejmste/90264

Hwang, G.-J., \& Chang, S.-C. (2015). Effects of a peer competition-based mobile learning approach on students' affective domain exhibition in social studies courses. British Journal of Educational Technology, 47(6), 12171231. https://doi.org/10.1111/bjet.12303

Hwang, W. Y., Shih, T. K., Ma, Z. H., Shadiev, R., \& Chen, S. Y. (2016). Evaluating listening and speaking skills in a mobile game-based learning environment with situational contexts. Computer Assisted Language Learning, 29(4), 639-657. https:/ / doi.org/10.1080/09588221.2015.1016438

Hwang, W.-Y., Huang, Y.-M., Shadiev, R., Wu, S.-Y., \& Chen, S.-L. (2014). Effects of using mobile devices on English listening diversity and speaking for EFL elementary students. Australasian Journal of Educational Technology, 30(5), 503-516. https://doi.org/10.14742/ajet.237

Ivić, V., \& Jakopec, T. (2016). Using mobile application in foreign language learning: a case study. Libellarium, 9(2), 217-230. https://doi.org/10.15291/libellarium.v9i2.288

Jin, W., \& Zhirui, D. (2017). Research on mobile learning model of college English based on WeChat platform. EURASIA Journal of Mathematics Science and Technology Education, 13(8), 5847-5853. https://doi.org/10.12973/eurasia.2017.01034a

Kalyuga, S., Ayres, P., Chandler, P., \& Sweller, J. (2003). The expertise reversal effect. Educational Psychologist, 38(1), 23-31. https://doi.org/10.1207/S15326985EP3801_4

Kılıç, E., \& Karadeniz, Ş. (2004). Hiper ortamlarda öğrencilerin bilişsel yüklenme ve kaybolma düzeylerinin belirlenmesi, (Specifying students' cognitive load and disorientation level in hypermedia). Journal of Educational Administration in Theory and Practice, 40, 562-579.

Kim, D., \& Kim, D. (2012). Effect of screen size on multimedia vocabulary learning. British Journal of Educational Technology, 43(1), 62-70. https:/ / doi.org/10.1111/j.1467-8535.2010.01145.x

Kim, H.-S. (2013). Emerging mobile apps to improve English listening skills. Multimedia-Assisted Language Learning, 16(2), 11-30. 
Klatzky, R. L., Wu, B., Shelton, D., \& Stetten, G. (2008). Effectiveness of augmented reality visualization versus cognitive mediation for learning actions in near space. ACM Transactions on Applied Perception (TAP), 5(1), 123. https:/ / doi.org/10.1145/1279640.1279641

Kuznekoff, J. H., \& Titsworth, S. (2013). The impact of mobile phone usage on student learning. Communication Education, 62(3), 233-252. https:/ / doi.org/10.1080/03634523.2013.767917

Liaw, S-S., Hatala, M., \& Huang, H-M. (2010). Investigating acceptance toward mobile learning to assist individual knowledge management: Based on activity theory approach. Computers \& Education, 54, 446-454. https:// doi.org/10.1016/j.compedu.2009.08.029

Lin, M.-H., Chen, H.-C., \& Liu, K.-S. (2017). A study of the effects of digital learning on learning motivation and learning outcome. EURASIA Journal of Mathematics Science and Technology Education, 13(7), 3553-3564. https://doi.org/10.12973/eurasia.2017.00744a

Liu, T.-Y., \& Chu, Y.-L. (2010). Using ubiquitous games in an English listening and speaking course: Impact on learning outcomes and motivation. Computers $\mathcal{E}$ Education, 55(2), 630-643. https:// doi.org/10.1016/j.compedu.2010.02.023

Lu, T., \& Yang, X. (2018). Effects of the visual/verbal learning style on concentration and achievement in mobile learning. EURASIA Journal of Mathematics, Science and Technology Education, 14(5), 1719-1729. https://doi.org/10.29333/ ejmste/85110

Miles, M. B., \& Huberman, A. M. (1994). Qualitative data analysis (2nd edition). Thousand Oaks, CA: Sage Publications.

Milutinović, M., Labus, A., Stojilkovic, V., Bogdanovic, Z., \& Despotovic-Zrakic, M. (2015). Designing a mobile language learning system based on lightweight learning objects. Multimedia Tools and Applications, 74. https://doi.org/10.1007/s11042-013-1704-5

Motiwalla, L. F. (2007). Mobile learning: A framework and evaluation. Computers \& Education, 49(3), 581-596. https:/ / doi.org/10.1016/j.compedu.2005.10.011

Ophir, E., Nass, C., \& Wagner, A. D. (2009). Cognitive control in media multitaskers. PNAS, 106(37), 15583-15587. https://doi.org/10.1073/pnas.0903620106

Ozer, O., \& Kılıç, F. (2017). Mobil öğrenme araçlarını kabul ölçeği: geçerlik-güvenirlik çalışması (The mobile learning tools acceptance scale: development and validation). Turkish Studies, 12(25), 577-588, https:// doi.org/10.7827/TurkishStudies.12378

Paas, F., \& Ayres, P. (2014). Cognitive load theory: A broader view on the role of memory in learning and education. Educational Psychology Review, 26(2), 191-195. https:/ / doi.org/10.1007/s10648-014-9263-5

Paas, F., \& Merrienboer, J. J. G. (1993). The efficiency of instructional conditions: an approach to combine mental effort and performance measures. Human Factors, 35(4). https:// doi.org/10.1177/001872089303500412

Paas, F., Tuovinen, J. E., Tabbers, H., \& Van Gerven, P. W. M. (2003). Cognitive load measurement as a means to advance cognitive load theory. Educational Psychologist, 38(1), 63-71. https:/ / doi.org/10.1207/S15326985EP3801_8

Paas, F., van Gog, T., \& Sweller, J. (2010). Cognitive load theory: new conceptualizations, specifications, and integrated research perspectives. Educational Psychology Review, 22, 115-121. https:/ / doi.org/10.1007/s10648-010-9133-8

Pegrum, M., Oakley, G., \& Faulkner, R. (2013). Schools going mobile: A study of the adoption of mobile handheld technologies in Western Australian independent schools. Australasian Journal of Educational Technology, 29(1), 66-81. https:/ / doi.org/10.14742/ajet.64

Rogers, K. D. (2011). Mobile learning devices. United States of America: Solution Tree Press.

Salvetti, F., \& Bertagni, B. (2016). Interactive holograms and tutorials in healthcare education: Case studies from the e-REAL® experience. International Journal of Advanced Corporate Learning, 9(2), 13-19, https:// doi.org/10.3991/ijac.v9i2.5988

Samaha, M., \& Hawi, N. S. (2016). Relationships among smartphone addiction, stress, academic performance, and satisfaction with life. Computers in Human Behavior, 57, 321-325. https:/ / doi.org/10.1016/j.chb.2015.12.045

Shadiev, R., Hwang, W.-Y., Huang, Y.-M., \& Liu, T.-Y. (2015). The impact of supported and annotated mobile learning on achievement and cognitive load. Educational Technology E Society, 18(4), 53-69.

Soruç, A., \& Tekin, B. (2017). Vocabulary learning through data-driven learning in an English as a second language setting. Educational Sciences: Theory \& Practice, 17, 1811-1832. https:/ / doi.org/10.12738/estp.2017.6.0305

Stockwell, G. (2010). Using mobile phones for vocabulary activities: Examining the effect of the platform. Language Learning \& Technology, 14(2), 95-110. 
Sung, Y., Chang, K., \& Liu, T. (2016). The effects of integrating mobile devices with teaching and learning on students' learning performance: A meta-analysis and research synthesis. Computers $\mathcal{E}$ Education, 94. https://doi.org/10.1016/j.compedu.2015.11.008

Sung, Y.-T., Chang, K.-E., \& Yang, J.-M. (2015). How effective are mobile devices for language learning? A metaanalysis. Educational Research Review, 16, 68-84. https:/ / doi.org/10.1016/j.edurev.2015.09.001

UNESCO. (2012). Working paper series on mobile learning: turning on mobile learning in Latin America. Paris: UNESCO.

Van Merrienboer, J. J. G., \& Sweller, J. (2005). Cognitive load theory and complex learning: Recent developments and future directions. Educational Psychology Review, 17(2). http:/ / doi.org./10.1007/s10648-005-3951-0

Vazquez-Cano, E. (2014). Mobile distance learning with smartphones and apps in higher education. Educational Sciences: Theory E Practice, 14(4), 1505-1520. http:/ / doi.org/10.12738/estp.2014.4.2012

Wang, R., Wiesemes, R., \& Gibbons, C. (2012). Developing digital fluency through ubiquitous mobile devices: findings from a small-scale study. Computers $\mathcal{E}$ Education, 58(1). https:// doi.org/10.1016/j.compedu.2011.04.013

Wang, S., \& Smith, S. (2013). Reading and grammar learning through mobile phones. Language Learning $\mathcal{E}$ Technology, 17(3), 117-134.

Wong, A., Leahy, W., Marcus, N., \& Sweller, J. (2012). Cognitive load theory, the transient information effect and e-learning. Learning and Instruction, 22(6), 449-457. https:/ / doi.org/10.1016/j.learninstruc.2012.05.004

Zheng, Q., Chen, T., \& Kong, D. (2017). An empirical study on context awareness integrated mobile assisted instruction and the factors. EURASIA Journal of Mathematics Science and Technology Education, 13(6), 17371747. https:/ / doi.org/10.12973/eurasia.2017.00695a

\section{http://www.ejmste.com}

